\title{
FUNDAMENTOS DA EDUCAÇÃO: ONTOLOGIA E EPISTEMOLOGIA EM MARX E FREIRE
}

\author{
FUNDAMENTALS OF EDUCATION: ONTOLOGY AND EPISTEMOLOGY IN MARX AND FREIRE
}

FUNDAMENTOS DE LA EDUCACIÓN: ONTOLOGÍA Y EPISTEMOLOGÍA EN MARX Y FREIRE

\author{
TADDE, Paulo Eduardo Dias ${ }^{1}$ \\ PALUDO, Conceição²
}

\begin{abstract}
RESUMO
Utilizando a pesquisa bibliográfica, o objeto deste trabalho é analisar as diferenças e aproximações na Ontologia e na Epistemologia e Teoria do Conhecimento entre Marx e Freire. Para atender o proposto, parte-se da formação do ser social e do conhecimento, nas perspectivas da emancipação e libertação. A análise é desenvolvida através dos conceitos de cultura e trabalho, na ontologia; e de problematização e contradição, na epistemologia. O entendimento é que o aprofundamento do proposto é fundamental para os processos de formação humana emancipadores e libertadores.
\end{abstract}

Palavras-chave: Ontologia. Epistemologia. Problematização e contradição.

\section{ABSTRACT}

Using the bibliographical research, the object of this work is to analyze the differences and approximations in Ontology and Epistemology and Knowledge Theory between Marx and Freire. In order to attend the proposed, it starts with the formation of the social being and knowledge, in the perspective of emancipation and liberation. The analysis is developed through the concepts of culture and work, in the ontology; And of problematization and contradiction, in epistemology. The understanding is that the deepening of the proposed is fundamental for the processes of human formation emancipating and liberating.

Keywords: Ontology. Epistemology. Problematization and contradiction.

\section{RESUMEN}

Utilizando la pesquisa bibliográfica, el objeto de este estudio es analizar las diferencias y aproximaciones en la Ontología y en la Epistemología y Teoría del Conocimiento entre Marx y Freire. Para cumplir con lo propuesto, se parte de la formación del ser social y del conocimiento, en las perspectivas de la emancipación y liberación.El análisis se desarrolla a través de los conceptos de cultura y trabajo, en la ontología; y de problematización y contradicción, en la epistemología. El entendimiento es que la profundización de lo propuesto es fundamental para los procesos de formación humana emancipadores y libertadores.

Palabras clave: Ontología. Epistemología. Problematización y contradicción.

\footnotetext{
1 Universidade Federal do Rio Grande do Sul- UFRGS - Porto Alegre - Rio Grande do Sul - Brasil

${ }^{2}$ Universidade Federal do Rio Grande do Sul- UFRGS - Porto Alegre - Rio Grande do Sul - Brasil
} 


\section{INTRODUÇÃO}

O objetivo geral deste trabalho é realizar um estudo bibliográfico comparativo, tendo como foco a análise das diferenças e aproximações na Ontologia, na Epistemologia e na Teoria do Conhecimento, entre Marx e Freire.

O artigo se justifica pela relevância do debate proposto, em um momento em que o mundo passa por um retrocesso ético, político e gnosiológico. No aspecto ético, observa-se a emergência da apologia à violência como "discurso da normalidade" e, sobretudo, a ampliação da violência, propriamente dita, no conjunto das relações sociais. Hoje, além da violência ordinária, enraizada, principalmente, nas profundas desigualdades sociais, têm-se, também, a violência decorrente do preconceito em suas múltiplas formas. Vive-se um tempo de banalização da vida. No aspecto político, há a desconstrução da perspectiva da esquerda, que já havia sofrido um duro golpe com a "queda do muro" de Berlim. Setores dominantes, de forma articulada, ou não, vinculam as perspectivas populares e democráticas à ideia de atraso, retrocesso, corrupção, incompetência, etc., como forma de inviabilizar, qualquer projeto de natureza contra-hegemônica ao neoliberalismo, ainda que sem alteração essencial das estruturas do sistema socioeconômico dominante. No campo gnosiológico, vive-se um momento de séria indigência intelectual, onde os conhecimentos científico e filosófico são colocados na "vala comum" das outras formas de "conhecimento", como o conhecimento vulgar, por exemplo, imediatista, difuso, fragmentado e não sistematizado. D'outra banda, paradoxalmente, a nominada "sociedade do conhecimento" dá ênfase àquilo que ela chama de "conhecimento tácito", construído a partir das experiências subjetivistas e individuais do(a) pesquisador(a), como forma relevante de conhecimento, inclusive frente ao conhecimento científico. Outro conhecimento considerado importante nesses tempos de falência gnosiológica é o denominado "conhecimento eficiente", um conhecimento a serviço das demandas do mercado, em uma perspectiva neoliberal, representado, em certa medida, pela Reforma do Ensino Médio, no Brasil e da tramitação do projeto da "Escola Sem Partido", que, em síntese, busca abolir o pensamento crítico da escola pública brasileira.

As escolhas da Ontologia, da Epistemologia e da Teoria do Conhecimento, de Marx e de Freire, dispensam maiores desforços justificadores, considerando-se o já exposto, acrescido da necessidade, cada vez mais urgente, de retomar o debate dos fundamentos da formação humana que orientam nossas práticas, e a transformação radical da sociedade.

Para desenvolver o proposto, parte-se da formação do ser social e do conhecimento, nas perspectivas da emancipação e da libertação: quais as fronteiras das análises dos autores? Os itens seguintes são destinados à análise dos conceitos de cultura e trabalho, na Ontologia; e de problematização e contradição, na Epistemologia e Teoria do Conhecimento, seguidos da conclusão. 


\section{GÊNESE E DELIMITAÇÃO DO CAMPO DE ABORDAGEM}

Este item é de natureza introdutória e importante para o desenvolvimento deste artigo. Diz respeito à "gênese" e a "delimitação do campo de abordagem" em Marx e em Freire. A "gênese" se refere ao ponto de partida da análise de cada um e a "delimitação do campo de abordagem" busca as linhas limítrofes que "encerram" a práxis dos autores trabalhados.

Destarte, a gênese em Marx está na própria humanidade: "A primeira condição de toda a história humana é evidentemente a existência de seres humanos vivos" (MARX; ENGELS, s/d, p. 18). No mesmo sentido, para Paulo Freire a gênese também está "nos homens": "O ponto de partida deste movimento está nos homens mesmos" (FREIRE, 1987, p. 73).

Com efeito, o ponto de partida de suas abordagens os aproxima, pois, para ambos, o "germe" da história é físico, e não metafísico. É antropológico e não teológico, muito embora a concepção cristã de Freire. Assim, é a partir do ser humano, delimitado pela história - e não fora dela - que ambos realizam suas abordagens. É, portanto, na história que ocorre o movimento dos que a protagonizam, construindo-a e sendo por ela construídos, dialeticamente.

O objetivo da "delimitação" não é reducionista ou restritivo, mas de demarcação do campo de análise de Marx e de Freire. A abordagem de ambos é delimitada pela realidade, que se dá no espaço/tempo da história, de uma história que é dinâmica e não estática; de uma história que condiciona e é condicionada pelos seus protagonistas. Nesta perspectiva, o a-histórico jaz na exterioridade da totalidade analisada por Marx e Freire. Sobre isto, diz Freire (1995, p. 19): "A História é tão vir-a-ser quanto nós, seres limitados e condicionados, e quanto o conhecimento que produzimos. Nada por nós engendrado, vivido, pensado e explicitado se dá fora do tempo, da História. Ter certeza, estar em dúvida, são formas históricas de estar sendo". Diz, ainda: "Seria impensável um mundo onde a experiência humana se desse fora da continuidade, quer dizer, fora da História" ( Ibidem, p. 19).

É, pois, na história que acontece a possibilidade de progresso e de transformação. É só na história que se pode ser mais, ainda que em uma relação dialética de oposição e de complementariedade entre possibilidade e condicionamento, condicionamento e possibilidade.

A proposta de educação problematizadora deixa nítida a visão progressista de Freire (1987, p. 73):

A educação problematizadora, que não é fixismo reacionária, é futuridade revolucionária. Daí que seja profética e, como tal, esperançosa. Daí que corresponda à condição dos homens como seres históricos e à sua historicidade. Daí que se identifique com eles como seres mais além de si mesmos - como "projetos" -, como seres que caminham para frente, que olham para frente; como seres a quem o imobilismo ameaça de morte; para quem o olhar para trás não deve ser uma forma nostálgica de querer voltar, mas um modo de melhor conhecer o que está sendo, para melhor construir o futuro. 
A ideia de progresso também está presente em $\mathrm{Marx}^{3}$, no âmbito de sua teoria da história, o mesmo ocorrendo em relação ao marxismo, ressalvadas as exceções ${ }^{4}$. Todavia, não se trata de um progresso linear, sem sobressaltos. É o progresso no sentido de que a história está em permanente movimento, permeada por contradições, não sendo algo dado e acabado: é um permanente devir. Freire também não vê o progresso de forma gradual, estruturada e harmônica, embora sua influência cristã, justamente porque sua análise não é a-histórica. Nesse sentido, revela: "Assim é que sempre entendi Deus - uma presença na História que não me proíbe de fazê-la, mas me empurra em favor da transformação do mundo, com o que se restaura a humanidade de exploradores e de fracos" (FREIRE, 1995, p. 85).

Em síntese, para ambos o ser humano é o princípio, a "gênese" da História e todas as formas de relações intersubjetivas e dos sujeitos com o meio acontecem no espaço/tempo da realidade; uma realidade que se desenvolve na História.

\section{ONTOLOGIA: CULTURA EM FREIRE E TRABALHO EM MARX}

Feitas essas considerações iniciais, relacionadas com o ponto de partida e a delimitação do campo de análise de Marx e de Freire, passa-se, a seguir, à análise da Ontologia e da Teoria do Conhecimento, para ambos.

Para Marx, o trabalho constitui o ser social. Pelo trabalho o ser humano se constrói em sua relação com a natureza e com os outros seres humanos. O homem e a mulher, diferentemente do animal, necessitam transformar a natureza para sobreviver. A transformação da natureza, no princípio, tinha por objetivo o atendimento das necessidades vitais do ser humano. Com o transcorrer do tempo, a relação do ser com outros seres e do ser com a natureza vai atingindo maiores graus de complexidade e sofisticação, criando "novas necessidades", novas exigências. Assim, é pelo trabalho que o homem se humaniza; que o "ser em si" vai passando a condição de "ser para si", adquirindo a consciência da sua existência e da necessidade de provê-la pela atividade transformadora na natureza (MARX, 2010).

Para Freire, a ontologia está na cultura5. Assim, se a cultura é ontológica em Freire, qual a Ontologia da cultura para Freire? Basicamente, cultura para Freire (2005) é a transformação da natureza pelo trabalho no curso da história. Seu conceito de cultura é amplo, porque envolve a transformação material e a transformação imaterial da natureza, neste último caso da própria natureza humana, como, também, da sociedade, objetiva e subjetivamente. Envolve, portanto, a relação do ser humano com a natureza, dos seres humanos entre si e do ser humano com os símbolos por ele produzidos.

\footnotetext{
3 Vale conferir em(BOTTOMORE, 2012, p. 447).

${ }^{4}$ Confira em (BOTTOMORE, 2012, p. 448).

5Para aprofundar(OSOWSKI, 2008, p. 107-108). 
Prefaciando a Pedagogia do oprimido, diz Fiori (1987, p. 18): "A cultura marca o aparecimento do homem no largo processo da evolução cósmica" Com efeito, Freire dá ênfase à cultura como resultado da intervenção do homem na natureza, o qual ao fazer cultura humaniza-se. A pronúncia da palavra, que é manifestação cultural, forma e transforma o mundo. "A palavra instaura o mundo do homem (Ibidem, p. 19). "Não há homem absolutamente inculto: o homem 'hominiza-se' expressando, dizendo o seu mundo". A palavra, para Freire é práxis, "não apenas designa as coisas, transforma-as". Sobre isso, assevera Freire (1987, p. 77) que "Não há palavra verdadeira que não seja práxis. Daí que dizer a palavra verdadeira seja transformar o mundo".

A palavra, sem dúvidas, tem muita força no processo histórico, todavia, outros elementos, de igual ou maior importância, precedem a palavra na formação da "história e da cultura"; no processo histórico em geral, que é a intervenção material na natureza. E como se dá essa intervenção? Como se transforma a natureza em cultura? O próprio Freire responde:

\begin{abstract}
A diferença entre os dois, entre o animal, de cuja atividade, porque não constitui "atos-limites", não resulta uma produção mais além de si e os homens que, através de sua ação sobre o mundo, criam o domínio da cultura e da história, está em que somente estes são seres da práxis. Práxis que, sendo reflexão e ação verdadeiramente transformadora da realidade, é fonte de conhecimento reflexivo e criação. Com efeito, enquanto a atividade animal, realizada sem práxis, não implica criação, a transformação exercida pelos homens a implica. E é como seres transformadores e criadores que os homens, em suas permanentes relações com a realidade, produzem, não somente os bens materiais, as coisas sensíveis, os objetos, mas também as instituições sociais, suas ideias, suas concepções (FREIRE, 1987, p. 92).
\end{abstract}

Merece ênfase a seguinte afirmação "os homens que, através de sua ação sobre o mundo, criam o domínio da cultura e da história [...]". Neste fragmento, Freire é explícito ao asseverar que a cultura e a história são resultados da "ação" humana sobre o mundo e no mundo. Ora, como se dá a ação do homem na natureza para criar cultura? Através de um movimento material, mais especificamente manual, nos primórdios da civilização. Esse movimento material de construção de cultura é o trabalho. Com efeito, sem trabalho não há cultura, não há transformação da natureza, não há história. O trabalho está, pois, na ontologia da própria cultura, pois esta "não é" sem a ação humana transformadora (trabalho). A passagem do estado de natureza para o estado de cultura. $\mathrm{O}$ corte do galho de uma árvore, por exemplo, seu desbastamento, a extração de um minério e o seu polimento, para a construção de um machado primitivo são, simultaneamente, um ato cultural, um fato cultural e um fato histórico. Em todos eles acontece uma intervenção material (manual) consciente e teleológica do homem na natureza. Assim, o "germe" da cultura, no sentido de transformação da natureza é o trabalho.

Por outro lado, a palavra, que nasce de uma necessidade material de entendimento entre os seres humanos, também é uma expressão cultural e, como tal, resultado de um trabalho anterior, um trabalho de construção, organização, sistematização e disseminação de sinais sonoros ou gestuais, como meio de comunicação e entendimento entre os seres humanos de determinado grupo social.

No fragmento abaixo, Freire separa trabalho de cultura. O segundo como resultado do primeiro. O primeiro como ontológico ao segundo. Entretanto, o que afasta um pouco Freire de Marx no aspecto 
ontológico, em uma análise rigorosa das concepções de ambos, é que Freire pega como ontológico a consequência do resultado da ação humana intencional e não a causa: o trabalho. Neste sentido:

\begin{abstract}
E pareceu-nos que a primeira dimensão deste novo conteúdo com que ajudaríamos o analfabeto, antes mesmo de iniciar sua alfabetização na superação de sua compreensão mágica como ingênua e no desenvolvimento da crescentemente crítica, seria o conceito antropológico de cultura. A distinção entre os dois mundos: o da natureza e o da cultura. O papel ativo do homem em sua e com sua realidade. O sentido de mediação que tem a natureza para as relações e comunicação dos homens. A cultura como o acrescentamento que o homem faz ao mundo que não fez. A cultura como o resultado de seu trabalho. Do seu esforço criador e recriador. O sentido transcendental de suas relações. A dimensão humanista da cultura. A cultura como aquisição sistemática da experiência humana (FREIRE, 2005, p. 116-117).
\end{abstract}

Freire é claro em afirmar que somente se constrói cultura pelo trabalho: "A cultura como o resultado de seu trabalho" (Ibidem). Ora, sendo assim, em tese, não é a cultura que está na base da hominização do ser humano e da transformação da natureza - pois ela é efeito, e não causa - mas, sim, o trabalho. Todavia, ainda que Freire reconheça, como foi dito, que o trabalho é formador de cultura, o ontológico para ele reside no efeito cultura e não na causa trabalho, na relação do homem com a natureza e nas relações intersubjetivas. A "experiência humana", para ele, é adquirida através da cultura e não do trabalho, embora aquela seja resultado deste. Não que ele não reconheça o papel fundamental do trabalho na formação da cultura, mas aquele, em sua ontologia, está absorvido por esta.

Ainda sobre o tema (1978, p. 134), diz Freire, citando Marx:

A discussão em torno do trabalho, que "é, em primeiro lugar, um processo entre a natureza e o homem, processo em que este realiza, regula e controla, por meio de sua própria ação, seu intercâmbio de matéria com a natureza", abre, por sua vez, a possibilidade ao debate em torno da cultura, que, em si, constitui uma unidade de estudo das mais importantes. A cultura e a identidade nacional. As positividades e as negatividades desta cultura. A necessidade de superação das últimas, que Cabral costuma chamar de "fraquezas" da cultura. A cultura e a produção do arroz. A cultura e a saúde. A cultura e a comida. A cerâmica, a escultura em madeira, a dança. A invasão cultural. A alienação cultural.

Para Marx, o trabalho que humaniza não é o trabalho explorado, no sentido específico e genérico da expressão. Dessa forma, o status ontológico atribuído ao trabalho, por Marx, refere-se ao trabalho vivo, ao trabalho concreto, ao trabalho útil e não ao trabalho extrator de mais-valia: o trabalho morto, abstrato, reificante, o trabalho como valor de troca. O trabalho específico do modo de produção capitalista ou o trabalho explorado (sentido genérico de exploração) de qualquer natureza (como o trabalho escravo, por exemplo) não são ontológicos.

No tocante ao aspecto ontológico do trabalho (daquele que ao mudar a natureza, muda a própria "natureza" humana), diz Marx (2010, p. 211):

\footnotetext{
Antes de tudo, o trabalho é um processo de que participam o homem e a natureza, processo em que o ser humano, com sua própria ação, impulsiona, regula e controla seu intercâmbio material com a natureza. Defronta-se com a natureza como uma de suas forças. Põe em movimento as forças naturais de seu corpo - braços, pernas, cabeça, mãos -, a fim de apropriar-se dos recursos da natureza, imprimindo-lhes forma útil à vida humana. Atuando assim sobre a natureza externa e modificando-a, ao mesmo tempo modifica sua própria natureza. Desenvolve as potencialidades nela adormecidas e submete ao seu domínio o jogo das forças naturais. Não se trata aqui das formas instintivas, animais, de trabalho. Quando o trabalhador chega ao mercado para vender sua força de trabalho, é imensa a distância histórica que medeia entre sua condição
} 
e a do homem primitivo com sua forma ainda instintiva de trabalho. Pressupomos o trabalho sob forma exclusivamente humana.

O trabalho ontológico é o trabalho produtor de valor de uso. O trabalho produtor do valor de troca, no sistema capitalista, não é trabalho ontológico, porque é trabalho como meio e não como fim. É trabalho explorado. É trabalho que aliena. Neste sentido, refere Marx (2010, p. 64-65):

O trabalho, como criador de valores-de-uso, como trabalho útil, é indispensável à existência do homem - quaisquer que sejam as formas de sociedade -, é necessidade natural e eterna de efetivar o intercâmbio material entre o homem e a natureza e, portanto, de manter a vida humana.

Assim, sob o prisma ontológico, enquanto para Marx o ser humano transforma a natureza e se transforma pelo trabalho, para Freire o trabalho é o meio para se fazer cultura, ou seja, o ontológico para ele está no "efeito cultura" e não na "causa trabalho". Assim, para Freire, o ser humano humanizase pela cultura, que tem por "germe" (elemento ontológico) o trabalho.

\section{EPISTEMOLOGIA E GNOSIOLOGIA: PROBLEMATIZAÇÃO EM FREIRE E CONTRADIÇÃO EM MARX}

Feita a análise acima sobre o que diferencia Marx e Freire na ontologia. Passa-se, a seguir, à análise no campo da Epistemologia e da Teoria do conhecimento.

Blanché (1988, p. 9), sobre epistemologia diz o seguinte:

A palavra epistemologia, que significa literalmente teoria da ciência, só recentemente foi criada. Não figura no Littrénem no Novo Larousse ilustrado. Segundo o Dicionário de Robert, o seu aparecimento nos dicionários franceses data de 1906, no suplemento do Larousse ilustrado. Nessa mesma data, quando da composição do Vocabulário da filosofia de Lalande, Jules Lachier considerava o termo como um lamentável neologismo.

O objeto de estudo da Epistemologia é o conhecimento científico. Com efeito, a Epistemologia é espécie do gênero Teoria do Conhecimento, que estuda o conhecimento em sua totalidade, com esta, em regra, não se confundindo. Neste sentido, diz Blanché (1988, p. 18):

\footnotetext{
Em princípio, a relação da epistemologia com a teoria do conhecimento é a mesma da espécie com o género, limitando-se a epistemologia a essa forma única de conhecimento que é o conhecimento científico. Todavia, a distinção desaparece quando o género se encontra reduzido a uma única espécie, como acontece com os autores que reservam ao conhecimento científico o nome de conhecimento, sendo tudo o resto considerado como puro jogo verbal sem significado cognitivo.
}

Qual a questão fundamental da Teoria do Conhecimento, também aplicáveis à Epistemologia aqui especificamente no que concerne ao estudo do conhecimento científico? Segundo Santos (1963, p. 1221), a questão é: "pode o sujeito apreender realmente o objecto? A pergunta consiste, portanto, em querer saber se realmente se dá esse contacto entre o sujeito e o objecto". Santos (1963) aponta 
as respostas de cinco escolas, acerca da referida questão: "dogmática", "cépctica", "subjectivista" e "relativista", "pragmática" e "criticista".

A discussão sobre a realidade parte da prioridade entre o mundo e a consciência. Para os idealistas, o pensamento é prioritário, dele resultando a própria realidade. O antropológico, o gnosiológico e o axiológico precedem o ontológico da realidade, ou seja, eles produzem a própria realidade. De outro lado, para os materialistas dialéticos, como Marx e Engels (1982), a realidade tem prioridade em relação à consciência; ela é exterior à consciência, dela não dependendo. A realidade nasce com o mundo. Aqui ainda não se fala em realidade histórica, porque a História exige a presença do antropológico em sua constituição e desenvolvimento. O ontológico, desse modo, precede o antropológico, o gnosiológico e o axiológico. O ontológico precede o antropológico no sentido de que o ser da realidade não é produto do homem, não nasce com o homem, mas com o mundo. O ontológico da natureza precede o ontológico da História. O ontológico da História - este sim - tem por germe o antropológico.

Em relação ao conhecimento científico, especificamente no que concerne à sua construção, Marx (2010, p. 31), enfatizando a sua complexidade, aduz: "Não há estrada real para a ciência, e só têm probabilidade de chegar a seus cimos luminosos aqueles que enfrentam a canseira para galgá-los por veredas abruptas". Acrescenta, ainda: [...] "aliás, toda a ciência seria supérflua se houvesse coincidência imediata entre a aparência e a essência das coisas" (MARX, 2008b, p. 1080).

Freire (1980, p. 92), articula a ação cultural - que "tem lugar ao nível da superestrutura" (Ibidem, p. 88-89) - e a revolução cultural com o conhecimento científico, asseverando o seguinte:

Ação cultural e revolução cultural apóiam-se no conhecimento científico da realidade, mas na revolução cultural a ciência não está a serviço da dominação. Em dois pontos, porém, não há diferença entre a ação cultural para a libertação e a revolução cultural. Ambas têm na "dialética da sobredeterminação" a sua explicação necessária, e são ambas conscientizadoras (Freire (1980, p. 92).

Qual é, então, fundamentalmente, a ontologia da realidade para cada um, ou seja, o que é realidade? Na expressão de Zanella (2007, p. 118), realidade para Marx é "uma totalidade estruturada dialeticamente que pode vir a ser racionalmente compreendida" e para Freire é "o fenômeno", que é igual "aquilo que aparece à consciência”.

Bottomore (2012, p. 460-461), no tocante ao tema, referindo-se a Marx, diz:

\begin{abstract}
Marx está comprometido com o realismo em dois níveis: 1) um realismo simples, de senso comum, que afirma a realidade, a independência e a externalidade dos objetos; 2) um realismo científico, que afirma que os objetos do pensamento científico são estruturas reais irredutíveis aos eventos a que dão origem. A primeira acepção inclui, para Marx, tanto a independência essencial da natureza quanto o caráter extratológico da existência em geral (social ou natural), ou seja, "o sujeito real permanece fora da mente, tendo uma existência independente" (Grundrisse: Introdução). A segunda acepção, que justifica e aprimora a primeira, incorpora as ideias de que as estruturas explicativas, os mecanismos geradores ou (na terminologia favorita de Marx) as relações essenciais são a) ontologicamente distintas de, b) defasadas em relação a, c) talvez se encontrem mesmo em oposição aos fenômenos (ou formas sensíveis) a que dão origem.
\end{abstract}

Torres (1981, p. 28), no que se refere ao problema epistemológico para Freire, diz: 
Em relação ao problema epistemológico, o autor diz, em Educação como prática de liberdade: "Entendemos que, para o homem, o mundo é uma realidade objetiva, independente dele, possível de ser conhecida. É fundamental, contudo, partirmos de que o homem, ser de relações e não só de contatos, não apenas está no mundo, mas como mundo (TORRES, 1981, p. 28).

Para Freire (1986, p. 35), a realidade concreta é dada através da relação dialética entre subjetividade e objetividade, ou seja, ela é a totalidade da relação consciência-mundo.

Para mim, a realidade concreta é algo mais que fatos ou dados tomados mais ou menos em si mesmos. Ela é todos esses fatos e todos esses dados e mais a percepção que deles esteja tendo a população neles envolvida. Assim, a realidade concreta se dá a mim na relação dialética entre objetividade e subjetividade.

Diz, ainda, que a realidade objetiva é produto da ação humana, a qual, todavia, não existe por acaso e nem se transforma por acaso.

A realidade social, objetiva, que não existe por acaso, mas como produto da ação dos homens, também não se transforma por acaso. Se os homens são os produtores desta realidade e se esta, na inversão da práxis, se volta sobre eles e os condiciona, transformar a realidade opressora é tarefa histórica, é tarefa dos homens (FREIRE, 1987, p. 37).

De acordo com Freire, consciência e mundo se dão ao mesmo tempo. Refere Freire (1987, p. 70), que "A consciência e o mundo, diz Sartre, se dão ao mesmo tempo: exterior por essência à consciência, o mundo é, por essência, relativo a ela". Freire vê a realidade objetiva como o mundo em si, mais a percepção ${ }^{6}$ que o ser humano faz dele através da consciência. Nesse sentido, afirma que:

A consciência de, a intencionalidade da consciência, não se esgota na racionalidade. [...] É como uma totalidade - razão, sentimentos, emoções, desejos -, que meu corpo consciente do mundo e de mim capta o mundo a que se intenciona (FREIRE, 1995, p. 75-76).

O autor diz, ainda, que "A conscientização não está baseada sobre a consciência, de um lado, e o mundo, de outro; por outra parte, não pretende uma separação. Ao contrário, está baseada na relação consciência-mundo" (Freire, 1980, p. 26-27). Para Freire, a relação consciência/mundo acontece reciprocamente.

Marx fala em um realismo científico, afirmando que os objetos do pensamento científico são estruturas da realidade não redutíveis aos eventos que a originaram. Para ele, o mundo é anterior, exterior e independente à consciência. "Não é a consciência dos homens que determina o seu ser, mas, ao contrário, é o seu ser social que determina sua consciência” (MARX, 1982, p. 130).

Freire, à primeira vista, trabalha com uma postura "mista", ao responder a questão da prioridade entre a consciência e o mundo, afirmando que ambas ocorrem simultaneamente, ou seja, o conhecimento se dá, ao mesmo tempo, subjetivamente e objetivamente. Todavia, esse aparente ecletismo é esclarecido por Freire, afirmando o que segue: 
Mas, como não há homens sem mundo, sem realidade, o movimento parte das relações homemmundo. Daí que este ponto de partida esteja sempre nos homens no seu aqui e no seu agora que constituem a situação em que se encontram ora imersos, ora emersos, ora insertados (FREIRE, 1987, p. 74).

Diz, ainda, Freire (Ibidem, p. 92): "Daí em diante, este ser, que desta forma atua e que, necessariamente, é um ser consciência de si, um ser 'para si', não poderia ser, se não estivesse sendo, no mundo com o qual está, como também este mundo não existiria, se este ser não existisse". O autor fala sobre a impossibilidade de dicotomização entre consciência-mundo, um necessitando do outro para existir.

Por outro lado, o homem, que não pode ser compreendido fora de suas relações com o mundo, de vez que é um "ser-em-situação", é também um ser do trabalho e da transformação do mundo. O homem é um ser da práxis; da ação e reflexão. [...]. Atuando, transforma; transformando, cria uma realidade que, por sua vez, envolvendo-o, condiciona sua forma de atuar. (FREIRE, 2006, p. 28).

Nesse particular, existe uma diferença fundamental de ordem epistemológica, entre Freire e Marx: a perspectiva de Freire pode ser definida como "inclassificável", se a análise restringir-se aos dois grandes campos da filosofia ${ }^{7}$ que sustentam a discussão sobre a prioridade entre consciência e matéria: o idealismo e o materialismo. Todavia, se a discussão puder extrapolar esses dois campos, é possível cogitar, não sem risco de fortes críticas, que a posição de Freire, quanto à prioridade, segundo Zanella (2007, 113), é uma “concepção múltipla da realidade”; uma concepção mista.

Entende-se, pois, que, embora dialética, provavelmente dialético-fenomenológica ${ }^{8}$, a postura de Freire não é a mesma de Marx. Para Freire, a consciência e o mundo se dão ao mesmo tempo, dialeticamente, não havendo prioridade entre sujeito e objeto, mas, o mundo só passa a ser mundo a partir do momento em que é percebido pelo elemento humano. Marx, por seu turno, situa-se, notadamente, entre os materialistas dialéticos que "elevam a matéria a uma categoria de importância primordial" (TRIVIÑOS, 1987, p. 21).

No campo da Teoria do Conhecimento $^{9}$, no tocante à possibilidade de conhecimento da realidade, para Freire a realidade pode ser conhecida; ela "se dá como objeto cognoscível", diante da "qual o homem assume uma posição epistemológica” (FREIRE, 1980, p. 26). O mesmo ocorre em relação a Marx, ao defender ardorosamente o conhecimento científico como forma superior de conhecimento; um conhecimento infenso à influência da ideologia ${ }^{10}$.

\footnotetext{
7 "Isto significa que, diante do problema fundamental da Filosofia, o da ligação entre o material e o espiritual, não cabem senão duas respostas. Uma está representada pelo Idealismo Filosófico [...]. A outra pelo Materialismo Filosófico. [...]. Sendo assim, os idealistas acham que foi a consciência, a ideia, que criou a realidade objetiva, os materialistas consideram o espiritual como derivado do material" (TRIVIÑOS, 1987, p. 18).

8 "Minha perspectiva é dialética e fenomenológica" (TORRES, 1981, p. 125).

9 Para um maior aprofundamento, ver posição de Torres, sobre o tema(1981, p. 28).

10 Ideologia no restrito e negativo expresso na obra A Ideologia Alemã.
} 
O critério de verdade, para ambos, está na prática social. Marx (2009a, p. 120), demonstra seu critério de verdade na II Tese sobre Feuerbach:

A questão de atribuir ao pensamento humano uma verdade objetiva não é uma questão teórica, mas prática. É na práxis que o homem deve demonstrar a verdade, isto é, a realidade e a força, o caráter terreno do seu pensamento. A disputa acerca da realidade ou irrealidade do pensamento (visto isoladamente da práxis) é uma questão puramente escolástica.

Freire dá ênfase à prática como objeto de análise de sua reflexão crítica, fazendo com que a teoria seja tão concreta que se confunda com a prática, devendo, em relação a esta, todavia, ocorrer um distanciamento epistemológico enquanto objeto de análise.

É pensando criticamente a prática de hoje ou de ontem que se pode melhorar a próxima prática. O próprio discurso teórico, necessário à reflexão crítica, tem de ser de tal modo concreto que quase se confunda com a prática. O seu "distanciamento" epistemológico da prática enquanto objeto de sua análise, deve dela "aproximá-lo" ao máximo (Freire, 2005, p. 39).

A práxis "é reflexão e ação dos homens sobre o mundo para transformá-lo. Sem ela, é impossível a superação da contradição opressor-oprimido" (FREIRE, 1987, p. 38). Freire fala da "educação bancária" e da educação problematizadora. A primeira se constitui em "depósito de conhecimento", sem reflexão crítica, havendo a internalização acrítica de conteúdos, dificultando a construção do saber autêntico. A educação, nesta perspectiva, é formadora para o pensamento heterônomo, para a domesticação, adaptando as maiorias aos interesses da minoria dominante. "Na verdade, o que pretendem os opressores 'é transformar a mentalidade dos oprimidos e não a situação que os oprime', e isto para que, melhor adaptando-os a esta situação, melhor os dominem" (FREIRE, 1987, p. 60). A “educação bancária”, segundo Freire (1987) é uma negação à construção/transmissão do conhecimento. Ela é narrativa, memorizadora. Neste sentido, diz:

Não pode haver conhecimento pois os educandos não são chamados a conhecer, mas a memorizar o conteúdo narrado pelo educador. Não realizam nenhum ato cognoscitivo, uma vez que o objeto que deveria ser posto como incidência de seu ato cognoscente é posse do educador e não mediatizador da reflexão crítica de ambos (FREIRE, 1987, p. 69).

Em contraposição à "educação bancária", Freire (1987) propõe a "educação problematizadora", como forma de superação da contradição opressor-oprimido. As duas perspectivas são antagônicas, pois a primeira serve à adaptação e a segunda à libertação.

No que concerne à "educação problematizadora", "libertadora", refere Freire (1987, p. 68):

[...] Como situação gnosiológica, em que o objeto cognoscível, em lugar de ser o término do ato cognscente de um sujeito, é o mediatizador de sujeitos cognoscentes, educador, de um lado, e educandos, de outro, a educação problematizadora coloca, desde logo, a exigência da superação da contradição educador-educandos. Sem esta, não é possível a relação dialógica, indispensável à cognoscibilidade dos sujeitos cognoscentes, em torno do mesmo objeto cognoscível. 
Diz, ainda, sobre a "educação problematizadora", como concepção formativa para a superação da contradição oprimido-opressor:

\begin{abstract}
O antagonismo entre as duas concepções, uma "bancária", que serve à dominação; outra, a problematizadora, que serve à libertação, toma corpo exatamente aí. Enquanto a primeira, necessariamente, mantém a contradição educador-educandos, a segunda realiza a superação. Para manter a contradição, a concepção "bancária" nega a dialogicidade como essência da educação e se faz antidialógica; para realizar a superação, a educação problematizadora situação gnosiológica - a firma a dialogicidade e se faz dialógica (Ibidem, p. 68).
\end{abstract}

Marx, no Manifesto do Partido Comunista, utiliza do binômio opressor-oprimido para representar os polos na luta de classes. É possível que Freire tenha se inspirado em Marx para fazer tal representação na Pedagogia do Oprimido. Com efeito, abrindo o I Capítulo do Manifesto de 48, diz Marx (1990, p. 66):

Homem livre e escravo, patrício e plebeu, barão e servo, mestres e companheiros, numa palavra, opressores e oprimidos, sempre estiveram em constante oposição uns aos outros, envolvidos numa luta ininterrupta, ora disfarçada, ora aberta, que terminou sempre ou com uma transformação revolucionária de toda a sociedade, ou com o declínio comum das classes em luta.

No marxismo, como concepção de mundo, encontra-se uma filosofia social, que é a filosofia da práxis, muito utilizada por Freire; uma ciência social, pressupondo, intrinsecamente, uma epistemologia e, extrinsecamente, uma sociologia histórica; e um método, o materialismo histórico e dialético. $\mathrm{O}$ marxismo também é uma prática social revolucionária, uma postura perante o mundo e a vida. Os elementos de análise da realidade do método marxista são: fundamentalmente: historicidade, contradição, mediação e totalidade.

Assim, como Freire fala de uma "educação problematizadora" como forma da superação da contradição oprimido-opressor, Marx entende que a realidade é "essencialmente contraditória e em permanente transformação" (KONDER, 2008, p. 8). Na contradição, para Marx, os polos contrários, ao se negarem, não se excluem, mas formam "um conteúdo mais abrangente, novo e superior" (BOTTOMORE, 2012, p. 117). A contradição é, pois, categoria central para o marxismo, representada pela unidade dos contrários, que, segundo Bottomore (Ibidem) é a "[...] marca registrada de toda a dialética ontológica marxista [...].

Neste particular, tanto Freire quanto Marx proclamam que o processo de libertação/emancipação é amplo, é geral, envolvendo opressores e oprimidos. Não se liberta o oprimido sem que se liberte o opressor. Com efeito, "A grande tarefa humanista e histórica dos oprimidos", segundo Freire (1987, p. 30) é "libertar-se a si e aos opressores". Portanto, para Freire, a libertação do oprimido implica a libertação do opressor.

Na mesma linha, refere Marx (2008a, p. 191-192):

Uma classe oprimida é a condição vital de toda sociedade baseada no antagonismo das classes. A libertação da classe oprimida, portanto, implica necessariamente a criação de uma sociedade nova. Para que a classe oprimida possa se libertar, é preciso que os poderes produtivos já 


\begin{abstract}
adquiridos e as relações sociais existentes não mais possam coexistir. De todos os instrumentos de produção, o maior poder produtivo é a própria classe revolucionária. A organização dos elementos revolucionários como classe faz supor a existência de todas as forças produtivas que podiam gerar-se no seio da sociedade antiga. Quer isso dizer que, após a queda da antiga sociedade, haverá uma nova dominação de classe, ou resumindo, novo poder político? Não. A condição de libertação da classe laboriosa é a abolição de toda classe, assim como a condição de libertação do terceiro estado, da ordem burguesa, foi a abolição de todos os estados e de todas as ordens. A classe laboriosa substituirá, no decorrer de seu desenvolvimento, a antiga sociedade civil por uma associação que excluirá as classes e seu antagonismo, e não haverá mais poder político propriamente dito, visto que o poder político é exatamente o resumo oficial do antagonismo na sociedade civil.
\end{abstract}

Assim, a libertação do oprimido, para ambos, não significa uma inversão no processo de dominação, mas a superação da contradição de classes. O horizonte, para Marx, está na emancipação humana que consiste no desenvolvimento omnilateral do ser humano, na superação de sua condição de homem dividido, unilateral, mutilado, passando do reino da necessidade para o reino da liberdade. E o horizonte, em Freire, está na libertação, libertação esta que é também do opressor, porque o oprimido não se liberta sozinho, decorrendo da sua libertação, a libertação do opressor. Segundo Freire, a educação pode contribuir para o processo de libertação, embora, como ele mesmo diz, ela sozinha não liberta, mas sem ela não é possível à transformação.

\title{
CONCLUSÃO
}

Em conclusão, pode-se dizer que a gênese os aproxima, pois para ambos o princípio está no ser humano, para Marx, e no "homem", para Freire. O campo de delimitação da análise é a História, o que também os aproxima.

No aspecto ontológico, independentemente do conceito de cultura com o qual se trabalha, seja no sentido de produção humana, no sentido simbólico ou de civilização, para Freire a ontologia está na cultura, enquanto que para Marx no trabalho, embora Freire reconheça expressamente que o que faz cultura é trabalho. No que se refere ao aspecto gnosiológico, para os dois autores, o conhecimento é possível e sua autenticidade está na prática social.

A realidade, para ambos, é externa e independente da consciência. Todavia, epistemologicamente, para Freire, consciência e mundo se dão simultaneamente, enquanto que, para Marx, o mundo precede a consciência. Freire, portanto, na mesma linha de Sartre, coloca uma terceira hipótese entre os dois ramos da Filosofia sobre a precedência entre consciência e realidade. Todavia, no que concerne aos conceitos de problematização e contradição eles se aproximam, tendo em vista que é somente através deles que a história se põe em movimento no sentido de sua transformação.

O horizonte em Marx está focado na emancipação. Em Freire, na libertação. A libertação e a emancipação só são possíveis com a transformação radical da sociedade. Para tanto, para ambos, é necessário à superação da contradição entre opressor-oprimido, ou seja, a abolição do antagonismo de classes. 
Finalmente, é importante ressaltar a importância de retomar os fundamentos para a proposição e prática de processos educativos que se pautam pela perspectiva de fazer da educação uma 'ferramenta' de transformação da sociedade.

\section{REFERÊNCIAS}

1. BLANCHÉ, Robert. A Epistemologia. Tradução de Natália Couto. Lisboa: Editorial Presença, 1988.

2. BOTTOMORE, Tom. Dicionário do pensamento marxista. Tradução de Waltensir Dutra. Rio de Janeiro: Jorge Zahar, 2012.

3. FIORI, Ernani Maria. Prefácio da Pedagogia do oprimido. (In): FREIRE, Paulo. Pedagogia do Oprimido. 17. ed. Rio de Janeiro, Paz e Terra, 1987, p. 9-28.

4. FREIRE, Paulo. Cartas à Guiné-Bissau. 2. ed. Rio de Janeiro: Paz e Terra, 1978.

5. Conscientização: teoria e prática da libertação; uma introdução ao pensamento de Paulo Freire. 3. ed. São Paulo: Moraes: 1980.

6. Criando Métodos de Pesquisa Alternativa: aprendendo a fazê-la melhor através da ação". BRANDÃO, Carlos (ORG.). Pesquisa Participante. 6. ed. São Paulo: Editora Brasiliense, 1986. Pedagogia do Oprimido. 17. ed. Rio de Janeiro, Paz e Terra, 1987. A s sombra desta Mangueira. 2. ed. Olho D'água: São Paulo, 1995. . Educação como prática da liberdade. 28. ed. Rio de Janeiro: Paz e Terra, 2005.

10. . Extensão ou comunicação? 13. ed. Rio de Janeiro: Paz e Terra, 2006a./

11. KONDER, Leandro. O que é dialética. São Paulo: Brasiliense, 2008 (Coleção Primeiros Passos; 23).

12. MARX, Karl. Para a crítica da economia política. Tradução de José Arthur Giannotti e Edgar Malagodi. São Paulo: Abril Cultural, 1982. (Os economistas).

13. MARX, Karl. Miséria da Filosofia. Tradução: Torrieri Guimarães. 2. ed. São Paulo: Martin Claret, 2008ª (Coleção A Obra Prima De Cada Autor). 
14. MARX, Karl. O Capital. Crítica da Economia Política. Tradução de Reginaldo Sant'Anna. Livro III, v. 4, 5 e 6. Rio de Janeiro: Civilização Brasileira, 2008b.

15. MARX, Karl. O Capital. Crítica da Economia Política. Tradução de Reginaldo Sant'Anna. Livros I, v. 1 e 2. 27. ed. Rio de Janeiro: Civilização Brasileira, 2010.

16. MARX, Karl e ENGELS, Friedrich. Manifesto do Partido Comunista. Tradução de Marco Aurélio Nogueira e Leandro Konder. 3. ed. Rio de Janeiro: Vozes, 1990.

17. MARX, Karl; ENGELS, Fiedrich. A Ideologia Alemã: crítica da filosofia alemã mais recente. Tradução: Conceição Jardim e Eduardo Lúcio Nogueira. vol. I, 3. ed. Lisboa: Editorial Presença (Portugal); São Paulo: Livraria Martins Fontes (Brasil), [s/d].

18. MARX, Karl; ENGELS, Fiedrich. A Ideologia Alemã: crítica da filosofia alemã mais recente. Tradução: Conceição Jardim e Eduardo Lúcio Nogueira - vol. II, 3. ed. Lisboa: Editorial Presença (Portugal); São Paulo: Livraria Martins Fontes (Brasil), [s/d].

19. MARX, Karl. Teses sobre Feuerbach. In: A Ideologia Alemã. Tradução de Frank Müller. São Paulo: Martin Claret, 2009/a. (Coleção A Obra Prima De Cada Autor), p. 117/120.

20. OSOWSKI, Cecília Irene. In Dicionário Paulo Freire. Danilo R. Streck. Euclides Redin, Jaime José Zitkoski (orgs.) Belo Horizonte: Autêntica, 2008.

21. SANTOS, Mário Ferreira dos. Dicionário de Filosofia e Ciências Culturais. $1^{\circ}, 2^{\circ}, 3^{\circ} \mathrm{E} 4^{\circ}$ volumes, São Paulo: Editora Matese, 1963.

22. TADDEI, P. E. D. Marx e Freire: a exploração e a opressão nos processos de formação humana. Dissertação do Mestrado em Educação - Universidade Federal de Pelotas - UFPel, 2014.

23. TRIVIÑOS, Augusto Nibaldo Silva. Introdução à pesquisa em ciências sociais: a pesquisa quantitativa em educação. São Paulo: Atlas, 1987.

24. TORRES, Carlos Alberto. Leitura crítica de Paulo Freire. Tradução de Mônica Mattar Oliva. São Paulo, Loyola, 1981.

25. ZANELLA, José Luiz. Considerações sobre a filosofia da educação de Paulo Freire e o marxismo. Revista de Estudos de Educação, Sorocaba -SP, v. 9, n. 1, p. 101-122, maio 2007. Disponível em http://periodicos.uniso.br/ojs/index.php?journal=quaestio\&page=article\&op=view\&path\%5B $\% 5 \mathrm{D}=17$ 0\&path\%5B\%5D=170. Acesso em 02/01/201. 


\section{Paulo Eduardo Dias Taddei}

Mestre em Educação e doutorando em Educação na Universidade Federal de Pelotas. Universidade Federal de Pelotas - UFPEL - Pelotas - Rio Grande do Sul - Brasil.

\section{Conceição Paludo}

Doutora em Educação. Professora no curso de Licenciatura em Educação do Campo e pesquisadora na Universidade do Rio Grande do Sul - UFRGS, na Faculdade de Educação - Departamento de Estudos Básicos - e na Linha de Pesquisa Trabalho, Movimentos Sociais e Educação (TRAMSE). Unoversidade Federal do Rio Grande do Sul -UFRGS - Porto Alegre - Rio Grande do Sul - Brasil.

\section{Como citar este documento}

TADDEI, Paulo Eduardo Dias; PALUDO, Conceição. Fundamentos da educação: ontologia e epistemologia em Marx e Freire. Reflexão e Ação, Santa Cruz do Sul, v. 26, n. 1, jan/abr. 2018. ISSN 1982-9949. Disponível em: <https://online.unisc.br/seer/index.php/reflex/article/view/9051>. Acesso em: doi:http://dx.doi.org/10.17058/rea.v26i1.9051. 